Cunningham, A. B. (1996) Professional ethics and ethnobotanical research. In Selected Guidelines for Ethnobotanical Research: A Field Manual (ed. M. N. Alexiades), pp. 19-5I. New York: New York Botanical Garden.

McKenna, D. J. (2004) Clinical investigation of the therapeutic potential of ayahuasca: rationale and regulatory challenges. Pharmacology and Therapeutics, 102, I I 1-129.
Rodrigues, E. \& Carlini, E. A. (2004) Plants with possible action on the central nervous system used by a Quilombola group in Brazil. Phytotherapy Research, 18, 748-753.

Rodrigues, E. \& Carlini, E. A. (2005) Ritual use of plants with possible action on the central nervous system by the Krahô Indians, Brazil. Phytotherapy Research, 19, 129-135.

Schultes, R. E. (1993) Plants in treating senile dementia in northwest Amazon. Journal of Ethnopharmacology, 38, 129-135.

\title{
Earthquake 2005: challenges for Pakistani psychiatry
}

\author{
Murad M. Khan MRCPsych
}

Professor, Department of Psychiatry, Aga Khan University, PO Box 3500, Stadium Road, Karachi 74800, Pakistan, email murad.khan@aku.edu

t 8.52 a.m. on 8 October 2005 an earthquake measuring 7.6 on the Richter scale struck the northern part of Pakistan and devastated large areas of North West Frontier Province and Azad Kashmir. Almost 90000 people died and many thousands were reported missing. Half the dead were estimated to be children, killed in their classrooms. Some 3.5 million people were rendered homeless. The mountainous terrain made relief work a logistical nightmare.

\section{Mental health issues in disasters}

According to the World Health Organization (WHO), $3-4 \%$ of survivors are affected by severe mental disorders (psychosis, severe depression or anxiety), and up to $15 \%$ can be expected to suffer from mild to moderate mental disorders (Ashraf, 2005). In the context of Pakistan after the earthquake, this would mean between 120000 and 160000 in need of treatment for severe mental disorders and up to 600000 for mild to moderate disorders. It was obvious that mental health services as they existed were grossly inadequate to deal with the scale of the disaster.

\section{Why are mental health services so inadequate in Pakistan?}

Pakistan is a country with huge contradictions. On the one hand, it is the sixth most populous country in the world (its population is approximately I 50 million), one of the largest Muslim countries and a nuclear power. On the other hand, more than a third of its people live below the poverty line, the literacy rate is around $35 \%$ and its national health indicators make sorry reading. As in many other developing countries (Dyer, 2006), corruption has been one of the major impediments to progress. The lack of transparency and accountability coupled with poor governance has led to high failure rates for health initiatives in Pakistan.
Mental health services are poorly developed. Health spending is a pitiable $0.5-1 \%$ of gross national product. Mental health does not have a separate budget but is believed to account for $1 \%$ of the health budget. There is about I psychiatrist to $0.5-1$ million of the population, but the distribution is unequal, as most psychiatrists are in large urban centres, while more than $70 \%$ of the population live in rural areas.

Government primary health services and the few psychiatric facilities are poorly organised and resourced and are accessed only by the very poor. Most healthcare is out-of-pocket expenditure, with the private sector contributing $77-90 \%$ nationally. On the other hand, community-based prevalence studies give very high figures for common mental disorders, with an estimated 25-66\% of women and 10-40\% of men suffering from them (Mumford et al, 2000).

Psychiatry and behavioural sciences are neither taught nor examined as a separate subject on the undergraduate medical curriculum in most medical colleges in Pakistan. Most graduating doctors, therefore, have little exposure to mental health issues.

\section{Programmes galore}

After the earthquake, many different psychological programmes were launched by a variety of organisations. Even the computer giant IBM, in collaboration with the Ministry of Social and Population Welfare, flew in two experts from the USA to conduct trauma management workshops. While all these organisations were well intentioned, there was little coordination between them. Some programmes focused only post-traumatic stress disorder (PTSD), and others focused on generic counselling skills. Almost all the programmes had separate training manuals and teaching materials. The target audience was not clearly identified. In many cases the same people ended up in various workshops without any clear idea of how or where they were going to use their newly acquired
The author has been part of

a team that

has developed

and conducted

training of health

professionals

in primary care

health centres in

Kashmir and North

West Frontier

Province. 


\section{2}

There were

also questions

regarding

the ethics of

conducting

research on

disaster survivors.

How could it

be ensured that

survivors were not

used as research

guinea pigs?

\section{The Pakistan}

Psychiatric Society, the country's

main body of

psychiatrists,

which should and

could have played

a pivotal role in

mental health

activities following

the earthquake,

was marginalised. skills. Some participants were in administrative positions and had very little contact with survivors, and were unlikely to do so.

The lack of coordination led to inevitable confusion. How were the trainees to be deployed? Who would supervise them? How long should the psychosocial intervention continue? Should this be a voluntary or paid activity? Should people coming from abroad be allowed access to the survivors? How could vulnerable survivors be protected from well meaning but insensitive professionals? Were the so-called foreign experts aware of and sensitive to the sociocultural and religious values of the survivors?

There were also questions regarding the ethics of conducting research on disaster survivors. How could it be ensured that survivors were not used as research guinea pigs? Who would ensure their consent would not be obtained under duress or in compromised circumstances? How could it be ensured that research is not linked to aid? Were there any ethics review committees to vet these projects?

Many of the problems existed because there was no clear psychiatric leadership in the country. The Pakistan Psychiatric Society, the country's main body of psychiatrists, which should and could have played a pivotal role in mental health activities following the earthquake, was marginalised (Dawn, 2005).

\section{What can be done?}

\section{Looking beyond the disaster: investing in health systems}

It is imperative not to focus on short-term psychosocial relief programmes for survivors, as many organisations and individuals have done, but to look beyond the disaster. One-off programmes should be strongly discouraged. They are extremely expensive, are a waste of valuable resources and do not address the underlying mental health issues of the population. Without any proper mechanism for supervision and monitoring, they are virtually useless. Similarly, psychological debriefing as an early intervention after trauma is likely to be ineffective and some evidence suggests that some forms may actually be counterproductive, by slowing natural recovery (van Emmerik et al, 2002).

Instead, there is a need to establish long-term, sustainable and culturally relevant health systems, with a primary care/public health approach, of which mental health is an integral part (van Ommeren et al, 2005). The advantage of this would be its greater acceptability than any stand-alone mental health programme. The establishment of primary care facilities in the affected areas is necessary, as is mental health training for primary care physicians and nurses, followed by supervision and monitoring of their acquired skills. The training of primary care professionals should include the recognition and management of mental disorders using both pharmacological and non-pharmacological approaches. Use of counselling (Ali et al, 2003) and a cognitive-behavioural model for patients with medically unexplained symptoms (Sumathipala et al, 2000) are just two examples of the latter. The critical issues here again are post-training supervision and monitoring.

\section{Need for national coordination}

There is an urgent need for national coordination of all relief work related to mental health. At the moment there is very little, and organisations have pursued their own programmes. In many cases there has been duplication of work while some areas are without any mental health input. Efforts should be made to standardise training through manuals and 'master' trainers, to ensure a uniform level of training.

\section{Programmes anchored in integrity}

Although the need for psychosocial interventions is increasingly recognised, it is imperative that professionals work in a concerted manner. The Pakistan Psychiatric Society can take on the important role of bringing together all mental health professionals. This will be possible only if there is a new approach, based on principles of integrity, honesty, fairness, competence and professionalism. All office holders of the Society should be elected by a democratic and transparent process. The Society should aim to become the authoritative voice of psychiatry in Pakistan.

It is vital that any mental health programme that is developed and adopted is strongly anchored in integrity. There must be complete transparency and full accountability of all processes and individuals involved in programmes, so that pilferage, fraud and cheating, endemic in many respects in Pakistan, are neutralised.

\section{Expatriate Pakistani mental health professionals}

Following the disaster, many expatriate Pakistani mental health professionals offered their time, money and expertise for psychosocial relief work. While some groups were well organised, others were not, and many had little idea how their expertise could be best used. The most cost-effective use of their time and expertise would be in the area of training of local health professionals, capacity-building and strengthening of local health systems. This, rather than the one-off PTSD or counselling skills programmes, which are neither needed nor sustainable in the long term, would ensure the best 'returns' on their investment. It is imperative that expatriate professionals interact with credible institutions and individuals in Pakistan and commit themselves to raising the standard of psychiatry in the country in the long term.

\section{Facing the challenges}

Today, Pakistani psychiatry stands at the crossroads. The challenges facing it, following the disaster, are enormous. Paradoxically, the tragedy has also given wide publicity to the importance of psychology and psychiatry as they relate to health and well-being.

Mental health professionals in Pakistan must seize the opportunity and use the influx of resources and 
raised awareness to establish mental health systems for the long term.

\section{References}

Ali, B., Rahbar, M., Naeem, S., et al (2003) The effectiveness of counseling on anxiety and depression by minimally trained counselors. American Journal of Psychotherapy, 57, 324-336.

Ashraf, H. (2005) Tsunami wreaks mental health havoc. Bulletin of the World Health Organization, 83, 405-406.

Dawn (2005) Thatta: composition of task force criticized. Dawn, 26 November 2005. See http://www.dawn.com/2005// I/26/ local23.htm. Last accessed 20 May 2006.
Dyer, O. (2006) New report on corruption in health. Bulletin of the World Health Organization, 84, 84-85.

Mumford, D. B., Minhas, F. A., Akhtar, I., et al (2000) Stress and psychiatric disorder in urban Rawalpindi. British Journal of Psychiatry, 177, 557-562.

Sumathipala, A., Hewage, S., Hanwella, R., et al (2000) Randomized controlled trial of cognitive behaviour therapy for repeated consultations for medically unexplained complaints: a feasibility study in Sri Lanka. Psychological Medicine, 30, 747757.

van Emmerik, A. A., Kamphuis, J. H., Hulsbosch, A. M., et al (2002) Single session debriefing after psychological trauma: a metaanalysis. Lancet, 360, 766-77I.

van Ommeren, M., Saxena, S. \& Saraceno, B. (2005) Mental and social health during and after emergencies: emerging consensus? Bulletin of the World Health Organization, 83, 71-76.

\section{European Commission}

The Commission has launched a green paper on mental health for wide public consultation which is intended to lead to a European Union strategy. This is a response to the successful European ministerial meeting held in Helsinki in January 2005. Its overall aim is to develop evidence-based policies that will promote cooperation and coordination and better information in the service of improving 'mental health for all', as well as research and exchange of information in such areas as stigma, suicide, child conduct disorders, care of the elderly and social inclusion. The document can be found at http://europa.eu.int/ comm/health/ph_determinants/life_style/mental/ green_paper/mental_gp_en.pdf

\section{News from the Association of European Psychiatrists (AEP)}

Three AEP Research Prizes, worth $€ 2500$ each, were awarded in Nice on 8 March 2006, during the closing ceremony of the 14th European Congress of Psychiatry. The prizes were awarded by Henning Sass, AEP President, to those young psychiatrists, working in Europe, who had published the best scientific papers in the year 2005 in the following areas:

o 'Clinical psychopathology and refinement of psychiatric diagnostic categories', the winner of which was Dr Matthew Broome, from the Institute of Psychiatry, London, UK, for his paper on a clinical service for prodromal psychosis, published in European Psychiatry.

O 'Biological correlates and treatments of mental disorders', the winner of which was Dr Ursula Bailer, from the Medical University of Vienna, Austria, for her paper on receptor binding after recovery from anorexia nervosa, published in Archives of General Psychiatry. o 'Psychiatric epidemiology, social psychiatry and psychotherapeutic interventions in mental disorders', the winner of which was Dr Paul Ramchandani, from the University of Oxford, UK, for his paper on paternal depression in the postnatal period and child development, published in the Lancet.

The 15th European Congress of Psychiatry will be held in Madrid in March 2007 (see http://www.aep.lu).

\section{Quarterly Journal of Mental Health}

This new peer-reviewed international journal (published by Psychological Healthcare Ltd in London, England) will be complementary to the purposes of International Psychiatry. Its key aims and objectives are: to publish original research in all aspects of psychiatry, from the five continents; to promote debate on issues relevant to mental health; to raise awareness of developments in mental health service provision; to promote mental health service development in the developing world; to promote collaborative research between investigators from different countries. Those wishing to submit papers should send them directly to profcasey@ esatclear.ie or to manuscripts@qjmh.org.uk.

\section{World Congress of Psychiatry}

Invitation from Professor Juan E. Mezzich,

President of the WPA

The XIV World Congress of Psychiatry will take place in Prague, 20-25 September 2008. All of our 130 member societies and 60 scientific sections are expected to be present along with a full representation of all our partners in mental healthcare, from our patients (who are at the centre of our work) to health professionals, health planners and relevant industry (see http://www.wpa-prague2008.cz).
For contributions

to the News and

Notes column,

please contact

Brian Martindale FRCP FRCPsych, South

of Tyne Early

Intervention in

Psychosis Service,

Northumberland

Tyne and Wear

NHS Trust,

Monkwearmouth

Hospital,

Newcastle Road,

Sunderland SR5

$1 \mathrm{NB}$, UK, email

Brian.Martindale@

stw.nhs.uk

The World Health

Organization's

Child and

Adolescent

Mental Health

Atlas project

is a systematic attempt to collect

information on

existing services and resources. It is available online at http://www.who. int/mental_health/ resources/Child ado_atlas.pdf 